\title{
CORRIGENDUM
}

\section{Atypical lymphocytic leukemia and mantle cell lymphoma immunologically very close: flow cytometric distinction by the use of CD20 and CD54 expression}

V Deneys, L Michaux, P Leveugle, AM Mazzon, E Gillis, A Ferrant, JM Scheiff and M De Bruyère

Correction to: Leukemia (2001) 15, 1458-1465. DOI: 10.1038/sj/leu/2402200

Leukemia (2002) 16, 402. DOI: 10.1038/sj/leu/2402346

The authors wish to apologize that in the above paper an incorrect version of Figure 1 was published. The correct version appears below.
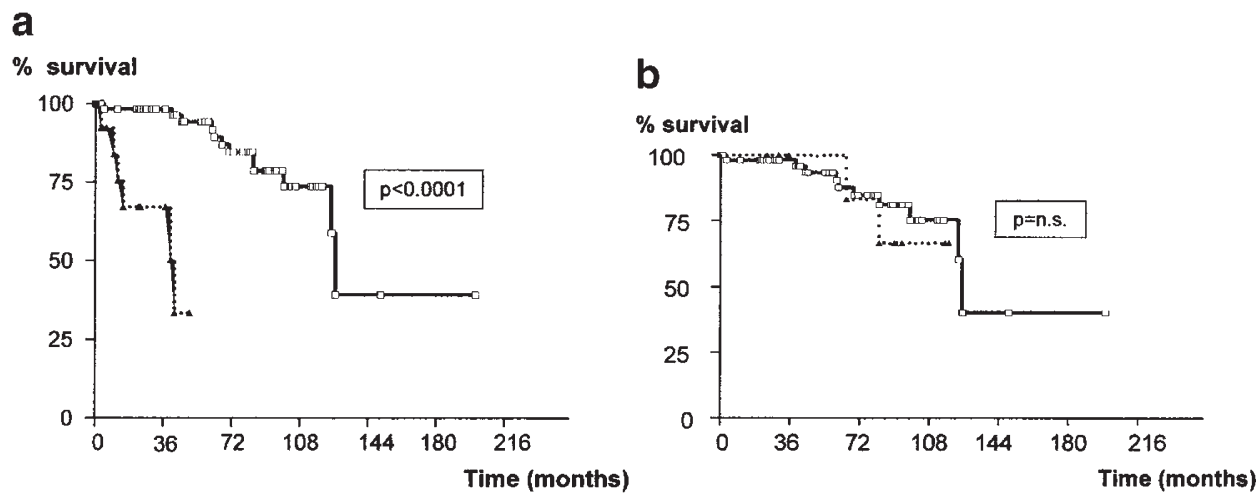

Figure 1 (a) Overall survival of the CLL patients (black line) and the MCL patients (dotted line). (b) Overall survival of the 'classical' CLL patients (black line) and the 'atypical' CLL patients (dotted line). 